\title{
Supervising the Efficiency of Governmental Control of Regional Economy: Legal Aspects and Economic Essence
}

\author{
Elena A. Murzina \\ Nina I. Larionova \\ Tatiana V. Yalyalieva \\ Volga State University of Technology, Department of Management and Law \\ Email:yal05@mail.ru
}

Doi:10.5901/mjss.2015.v6n2p370

\begin{abstract}
Efficient governmental control is an essential condition for the functioning of the state apparatus. Today, the governmental bodies are facing the task of improving the efficiency of the way they perform their functions, for this is what considerably determines the condition of the state budget, which produces an immediate effect on the people's welfare through the corresponding areas of the budget expenditures. The importance of finding a solution for the task stimulated us to perform this research. I believe developing methods for efficiency assessment of the taxation control of taxes and duties collected to the Russian budget system represents an important scientific and practical task and finding a solution for it will contribute to improvement of the quality of the entire social and economic policy of the state, including the taxation policy. The research shows that every country, including Russia, requires efficiency assessment of the governmental control. The central governmental bodies of Russia apply various internal criteria and efficiency parameters to assess the performance of the subordinate bodies. However, Russia is still in the process of establishing a unified methodology to assess the quality both of the taxation control in general and the controlling activities of particular taxation authorities.
\end{abstract}

Keywords: governmental control, economic institutions, legal regulation, effectiveness of institutions.

\section{Introduction}

Since there is no methodologically verified efficiency assessment of the governmental control, which would be approved at the federal level, the central state apparatus is unable to objectively compare the results obtained from particular areas of the controlling activities performed by the subordinate authorities, which should be aimed at discovering new tools and methods to implement controlling measures that can be used to rationalize the governmental control and improve its efficiency. The topicality of the governmental control development issue, as well as the problems of the taxation control efficiency improvement in Russia, made for choosing the subject of this study and predetermined the concept of this article, along with the goal, task and objects of the research. As a result of this work, we have carried out a comprehensive study of the theoretical bases of the governmental control. Formation of a certain type of market structures, may, on the whole, be regarded as a response to excessive transaction costs. At this point, integration processes in Russia are characterized by aggregation and consolidation of enterprises. This implicitly proves the desire for diversification and economic control of enterprise risks associated with imperfect institutional environment and excessive transaction costs. It should be noted that control over efficiency of costs or any other category may be an extremely complicated and expensive procedure. An example would be the control which the government exercises over taxpayers since it has to maintain the costly tax-collection apparatus.

One of the most interesting ways to optimize the efficiency control of transaction costs consists in eliminating excessive control procedures and reducing the amount of data being collected. The main principle that should be adhered to is reduction of excessive information, i.e. 'do not collect more information than you can process'.

Sometimes data collection services do not manage to analyze information, all their time is spent on collecting it. It would be reasonable to focus on weakest aspects, i.e. areas where problems arise more often. This would allow to solve the core of the problem more efficiently while saving transaction costs related to data collection and processing.

Integration trends in the Russian economy are mainly associated with transition processes and enterprises' adaptation to the imperfect market conditions. The natural reaction of a rational economic agent to excessive transaction 
costs would be trying to independently reduce them. But as a result, the reproduction system may fall into an institutional trap. Since it is impossible to rely on natural tendencies of transaction costs to decrease, the need arises for the government active interference in the process of their 'natural' reduction.

As a subject of government control, dual nature of transaction costs, especially transformation processes with a high share of informal sector, as well as significant difference in conditions of functioning of various types of markets require a differentiated approach to transaction costs reduction in the national economy.

Comprehensive mechanism for efficiency control of transaction costs which is used in economy to reduce them involves development of ideology, specification and protection of property rights, standardization of measurements, accounting and reporting, maintenance of monetary system, improvement of law enforcement effectiveness and efficiency, as well as implementation of measures aimed at eliminating unnecessary administrative burdens and infrastructure markets of various transactions.

The basic requirements of institutional changes include recognition of the critical role of the government control of economic development; government's commitment to economic development; accounting of institutional transformation costs; review of efficiency of the current control.

Governmental control is one of the most important ensuring instruments of a state. The activities of the controlling authorities are governed by a whole system of normative legal enactments.

Governmental control is performed by officials representing the authorized bodies, within their competences, by collecting explanations, checking the accounting and reporting information, inspecting the premises and territories used to gain income (profit), and by using other instruments provided by the law. One of the most significant areas of governmental control is financial control. Financial control is traditionally considered as a part of the governmental control system which covers the sphere of formation, distribution and use of the monetary funds. Financial control is control of the legality and appropriateness of the activities performed in the sphere of formation, distribution and use of the monetary funds of the state and municipalities, which is aimed at efficient social and economic development of the country and its regions. Representing a constituent part of the economic management, financial control ensures the interconnection between companies and the governmental bodies that have the corresponding rights and authorities.

In scientific and journalistic literature, governmental control is defined in the broad sense as a special method of ensuring legality. Its key tasks are ensuring that all the taxes and duties stipulated by the law are duly paid to the budgets of various levels and preventing tax evasion. In other words, governmental control means checking on how the laws are observed and elimination of errors and violations (Koteeswaran, Visu and Janet, 2012). For instance, Nikolaos, Petros, Eleni, Evangelos and Dimitrios, in their article, looks at governmental control from the position of the necessity to observe the financial discipline as a precondition for individuals and legal entities to properly fulfill their obligations to the state and considers fiscal supervision to be the major function of the taxation control system (Nikolaos, Petros, Eleni, Evangelos and Dimitrios, 2013). Larionova, Yalyalieva, Napolskikh, representatives of another school of economists and financiers introduce their grounds as follows: "Governmental control is a system of measures aimed at supervising the legality, appropriateness and effectiveness of the activities related to the formation of the monetary funds of the state at all the levels of management" (Larionova, Yalyalieva., Napolskikh, 2014). Some issues related to the improvement of the governmental control efficiency were also examined in the works by Shemyakina (Blumenthal \& Shemyakina, 2013). However, we find it possible to continue studying the subject. Certain theses were already mentioned in some of the works by the authors of this article (E. Murzina, 2014; T. Yalyalieva, 2014). We are going to proceed with the analysis here.

Trying to answer the question how and with what criteria should the effectiveness of taxation authorities be assesses, we came to the conclusion that all the methods can be divided into two groups for convenience. We consider the first group to consist of the so-called author's methods. They were developed by various scientists and represent rather theoretical products that can hardly be applied in practice by taxation authorities. The second group is a collection of the assessment criteria that are being implemented or used to be applied by taxation authorities. We believe the criteria used for the methods of the second group are of the greater importance to the practical efficiency assessment. The content of those criteria is important not only to governmental bodies but also to companies that the taxation control is applied to. Having examined the approaches to efficiency assessment of the controlling activities performed by governmental bodies, suggested by various scientists, and the methods that used to be or are still applied by governmental bodies, and upon analyzing their strong points and disadvantages, we proceeded with our study with the following aspects taken into account: first, the work of the governmental bodies should be studied with the help of both quantitative and qualitative parameters that represent the entire spectrum of the factors affecting the efficiency of their controlling measures; second, to ensure the correct efficiency assessment of the controlling activities it is required to use all the parameters in relative terms or as dynamic values. 


\section{Research Methodology}

We have developed a system of modern criteria and parameters to assess the efficiency of the controlling activities performed by governmental bodies. The suggested system contains three major blocks of criteria: 1) general efficiency assessment of the controlling activity; 2) assessment of the parameters related to organization and implementation of field audits; 3) assessment of the parameters related to organization and implementation of office audits. To make the analysis and develop appropriate efficiency assessment methods for the work done by governmental bodies, we used the information provided by the governmental bodies of the Mari El Republic, and by the taxation authorities in particular. The efficiency was analyzed by the major parameters of their activities. Here are the most popular coefficients and criteria, which can be divided into three group of parameters: a) general assessment of the controlling activity performed by a taxation authority; b) assessment of the organization and implementation of office tax audits; c) assessment of the organization and implementation of field tax audits. This system of parameters includes:

A. Dynamics of the payments additionally charged as resulting from the controlling activity:

$$
\Delta A=A_{t}+1-A_{t} \text {, }
$$

where A stands for the amount of the payments additionally charged as resulting from the controlling activity, and $t$ is one year.

This value represents the comparison of the amounts of the payments additionally charged for several reported periods, and any positive dynamics would mean improvement of the controlling activity efficiency.

B. Specific share of the payments additionally charged as resulting from the controlling activity in the total amount of the incoming payments:

$$
\text { Sadd }=\frac{A}{P} \times 100 \text {, }
$$

where A stands for the amount of the payments additionally charged as resulting from the controlling activity, and

$P$ is the total amount of the incoming payments.

This value is calculated as the ratio of the amount of the additionally charged payments to the total amount of the payments charged.

C. Specific share of the payments recovered as resulting from the controlling activity in the total amount of the additionally charged payments:

$$
\text { Srec }=\frac{R}{A} \times 100 \text {, }
$$

Where A stands for the amount of the payments additionally charged as resulting from the controlling activity, and

$\mathrm{R}$ is the total amount of the payments recovered to the budget system of Russia as resulting from the tax audit.

This value is calculated as the ratio of the amount of the payments recovered as resulting from the controlling activity to the amount of the payments additionally charged as resulting from the tax audits. It shows what share of the payments additionally charged came to the budget system.

D. General effectiveness coefficient:

$$
\text { Ceff }=\frac{R}{C} \times 100
$$
audit, and

where R stands for the amount of the payments recovered to the budget system of Russia as resulting from the tax

$\mathrm{C}$ is the costs of the activities performed by the taxation authority.

This value is calculated as the ratio of the amount recovered from the payments additionally charged as resulting from the tax audit to the amount of the costs of the activities performed by the taxation authority. It shows the effectiveness of the costs required for the recovery.

E. Legality coefficient of the extra charges resulting from tax audits:

$$
\text { Clegal }=\frac{A-D}{A} \times 100 \text {, }
$$

where $\mathrm{D}$ stands for the deduction amount of the payments additionally charged as resulting from the decisions of judicial and superior bodies, and

$\mathrm{A}$ is the amount of the payments additionally charged as resulting from the controlling activity.

This value represents the judicial acknowledgement of the legality of the fines and penalties imposed. The ideal value is $100 \%$. 


\section{Findings and Discussion}

Analyzing the efficiency of the controlling activities performed by the regional governmental bodies allows us to assess the total efficiency of the controlling activities performed by governmental bodies in general. The main quantitative parameter characterizing the work of governmental bodies is normally the amount of the payments additionally charged as resulting from the controlling activity and its dynamics as compared to the previous periods. Resulting from the controlling activities performed by the taxation authorities, the following amounts, including taxes, fines and penalties, were additionally charged in the corresponding reported periods: 1,004.5 million rubles in 2012, 881 million rubles in 2013 , and 806.9 million rubles in 2014. Thus, we see the total amount of the payments additionally charged going down within the period of the observation. In 2013 the extra charges reduced by $12.3 \%$ if compared to 2012, and it went down by $8.4 \%$ in 2014. In 2012, the specific share of the payments additionally charged as resulting from the audits in the total amount of the payments additional charged was $2.3 \%$ and $97.7 \%$ as resulting from the tax audits; in 2013 it was $9.7 \%$ and $90.3 \%$ correspondingly; and $3.3 \%$ and $96.7 \%$ in 2014 . The major source of the payments additionally charged is making field tax audits. These data show that the specific share of all the payments additionally charged as resulting from the controlling activities performed by the Department in the total amount of the payments recovered to the budget is going down within the period of the analysis. So, it was $13.74 \%$ in $2012,9.92 \%$ in 2013, and $9.67 \%$ in 2014 . The reduction of the value is mainly caused by the growth of the total amount of the payments recovered to the budget, while the charges resulting from the controlling activities are decreasing. When assessing the results of the work, we should take account of the fact that the amount of the taxes additionally charged often differs from the amount that reaches the budget then. As a rule, only $40 \%$ to $50 \%$ of the taxes and duties additionally charged as resulting from all kinds of tax audits (field and office audits) are actually recovered to the budget. To determine this value for the reported period, we will examine the recovery results of the taxes and penalties additionally charged.

Examining the approaches, suggested by various scientists, to the efficiency assessment of the controlling activities performed by the governmental bodies and the methods that the governmental bodies used to apply and are still applying and analyzing their strong points and disadvantages, we can come to the following conclusions: first, the work done by taxation authorities should be studies with both quantitative and qualitative parameters characterizing the entire spectrum of the factors that take effect on the efficiency of the controlling activities performed by those taxation authorities; second, to ensure the correct efficiency assessment of the tax audit performed by a tax inspectorate, all the parameters should be used in relative terms or as dynamic values. Here are the most popular coefficients and criteria that can be divided into three groups of parameters: a) general assessment of the controlling activity performed by the taxation authority; b) assessment of the organization and implementation of office tax audits; c) assessment of the organization and implementation of field tax audits. The efficiency analysis of the controlling activities performed by the Department of the Federal Taxation Service of Russia for the Mari El Republic, which was carried out with the help of this system of parameters, has shown the following results. The major efficiency parameter of the controlling activity, such as the amount of the payments additionally charged, decreased by 19\% in the period from 2012 to 2014 . The recovery level of the payments resulting from the controlling activity is extremely low and does not exceed $43 \%$ in the period of the analysis. However, within the period we can observe a growing trend for this value. The average legality coefficient of the taxes additionally charged in the period is $90 \%$, which shows that the quality of the work done both by the controlling department and the legal department during judicial proceedings is quite high. On the average, if considered for the entire country, this coefficient amounted to $72 \%$ in the same period.

\section{Concluding Remarks}

As seen from the data we obtained, the recovery level of the payments resulting from the controlling activity is extremely low; it did not exceed 43\% in the period of the analysis. In 2012 it was even less than $30 \%$. It means that only one third of the amount additionally charged reached the budget system of the country. At the regional level, this value is several points lower in the reported period than the average value for the country. However, within the period we can observe a growing trend for this value, which represents a positive result of the work done by the taxation authorities. The recovery value, as estimated per governmental body official, grew by $35 \%$ within the period. Totally for the entire country, it amounted to 978,000 rubles in 2012, 952,000 rubles in 2013, and 1,106,000 rubles in 2014.

The main reasons for the decrease of the value of the payments additionally charged as resulting from the field audits, if compared to the same value of the previous year, are reduction of the number of the audits performed, which, in turn, resulted from the reduction of the number of the officials who actually performed the field audits, and selection of the subjects to be included in the audit plan, basing on the recovery possibility factor applied to the payments additionally 
charged as resulting from the audits.

\section{Acknowlegments}

Thanks.This researchers was supported by the Ministry of Economic Development and Trade of the Mari El Republic (agreement No. 126/8 of October 8, 2013) and Volga State University of Technology, state-financed scientific-research work No 20 «Efficiency of state control in the sphere of economic activity of the region», No 9 «Development institutions of local markets and the formation of an innovative cluster».

\section{References}

Murzina, E. A. (2014) Fiscal nihilism of subjects of small and medium business as threat of economic security of Russia. New university: Economics \& law, 5-6, 83-87. http://dx.doi.org/10.15350/2221-7347.2014.5-6.00063

Yalyalieva, T. V. (2014) Problems and strategies of quality control of public services at the regional level. New university: Economics \& law, 7-8, 50-53. http://dx.doi.org/DOI: 10.15350/2221-7347.2014.7-8.0008

Blumenthal, O. I., Shemyakina, M.S. (2013). Improvement of system of tax deductions and regulation of a tax rate as ways of increase of efficiency of tax administration of receipts of the personal income tax. New university: Economics \& law, 9, 10-16.

Larionova N.I. , Yalyalieva T.V., Napolskikh D.L. Ensuring efficiency control of institutional. Environment of the cluster. doi:10.3844/ajassp.2014.1594.1597 Published Online 11 (9) 2014 (http://www.thescipub.com/ajas.toc)

Koteeswaran, S., P. Visu and J. Janet, 2012. A review on clustering and outlier analysis techniques in datamining. Am. J. Applied Sci., 9: 254-258.

Nikolaos, E., K. Petros, P. Eleni, P. Evangelos and V. Dimitrios, 2013. The impact of the Greek economic crisis on the Greek construction companies. Back to basics: The statistical cost accounting model. Am. J. Econom. Bus. Admin., 5: 168-174. DOI : 10.3844/ajebasp.2013.168.174 